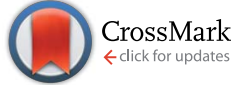

Cite this: J. Mater. Chem. A, 2014, 2 , 13835

Received 25th May 2014

Accepted 11th June 2014

DOI: $10.1039 / c 4 t a 02611 j$

www.rsc.org/MaterialsA

\section{Electrocatalysis of the hydrogen-evolution reaction by electrodeposited amorphous cobalt selenide films $\uparrow$}

\author{
Azhar I. Carim, ${ }^{a}$ Fadl H. Saadi, ${ }^{\text {bc }}$ Manuel P. Soriaga ${ }^{\text {cf }}$ and Nathan S. Lewis*acde
}

Using an electrochemical method under ambient conditions, crystallographically amorphous films of cobalt selenide have been deposited from aqueous solution onto planar Ti supports. These films have been evaluated as electrocatalysts for the hydrogen-evolution reaction. In $0.500 \mathrm{M} \mathrm{H}_{2} \mathrm{SO}_{4}$, the cobalt selenide films required an overpotential of $\sim 135 \mathrm{mV}$ to drive the hydrogen-evolution reaction at a benchmark current density of $-10 \mathrm{~mA} \mathrm{~cm}{ }^{-2}$. Galvanostatic measurements indicated stability of the electrocatalytic films for $>16 \mathrm{~h}$ of continuous operation at $-10 \mathrm{~mA} \mathrm{~cm}{ }^{-2}$. The facile preparation method, and the activity of the cobalt selenide films, suggest that electrodeposited metal chalcogenides are potentially attractive earth-abundant electrocatalysts for the hydrogen-evolution reaction.

The development of a technology capable of efficiently producing molecular hydrogen from water is a critical step toward the realization of a sustainable, renewable, and carbonneutral source of energy. The electrochemical half-reaction for this process, known as the hydrogen-evolution reaction (HER), typically exhibits sluggish kinetics at most cathodes, but is effectively catalyzed by noble metals such as Pt and Pd, which provide high cathodic current densities at modest overpotentials. ${ }^{1,2}$ Earth-abundant materials capable of catalyzing the HER are being vigorously sought to reduce the cost and increase the scalability of water-splitting systems. ${ }^{3-6}$ Catalysts that operate effectively in acidic aqueous solutions are of

${ }^{a}$ Division of Chemistry and Chemical Engineering, California Institute of Technology, Pasadena, CA 91125, USA.E-mail: nslewis@caltech.edu

${ }^{b}$ Division of Engineering and Applied Sciences, California Institute of Technology, Pasadena, CA 91125, USA

${ }^{c}$ The Joint Center for Artificial Photosynthesis, California Institute of Technology, Pasadena, CA 91125, USA

${ }^{a}$ Beckman Institute, California Institute of Technology, Pasadena, CA 91125, USA

${ }^{e}$ Kavli Nanoscience Institute, California Institute of Technology, Pasadena, CA 91125, USA

${ }^{f}$ Department of Chemistry, Texas A\&M University, College Station, TX 77843, USA $\dagger$ Electronic supplementary information (ESI) available: Detailed experimental methods, X-ray diffraction data, X-ray photoelectron spectra, calculation of turnover frequencies. See DOI: 10.1039/c4ta02611j particular interest to these efforts because acidic electrolytes are compatible with existing proton-exchange membranes and minimize the efficiency losses that can result from the formation of a $\mathrm{pH}$ gradient across the membrane., ${ }^{7,8}$

Effective catalysis of the HER in alkaline media has been demonstrated using earth-abundant transition metal alloys, most notably Ni-based alloys such as Ni-Mo. These highly active materials often reach a current density of $-10 \mathrm{~mA} \mathrm{~cm} \mathrm{~cm}^{-2}$, a benchmark value for photoelectrochemical water-splitting systems, ${ }^{3}$ with overpotentials $<100 \mathrm{mV}$ at $\mathrm{pH} \geq 14$, but are typically unstable in acidic media due to corrosive dissolution, at least when anodic current is passed through the material.,9-12 $\mathrm{Ni}-\mathrm{Mo}-\mathrm{N}, \mathrm{Co}_{0.6} \mathrm{Mo}_{1.4} \mathrm{~N}_{2}, \mathrm{MoB}, \mathrm{Mo}_{2} \mathrm{C}, \mathrm{Ni}_{2} \mathrm{P}, \mathrm{Ni}_{5} \mathrm{P}_{4}$ and CoP have exhibited stable catalysis of the HER in strongly acidic aqueous electrolytes, but of these materials only the phosphides have been demonstrated to produce current densities of $-10 \mathrm{~mA}$ $\mathrm{cm}^{-2}$ with overpotentials $<200 \mathrm{mV}{ }^{\mathbf{1 3 - 1 8}}$ Recently, transition metal chalcogenide materials, the prototypical example of which is $\mathrm{MoS}_{2}$, have attracted significant attention as HER electrocatalysts in acidic media. ${ }^{\mathbf{9}, 20}$ Accordingly, significant effort has been devoted to optimizing and engineering $\mathrm{MoS}_{2}$, and to a lesser extent $\mathrm{MoSe}_{2}, \mathrm{WS}_{2}$ and $\mathrm{WSe}_{2}$, to improve their catalytic performance, resulting in overpotentials of $<200 \mathrm{mV}$ for effecting HER current densities of $-10 \mathrm{~mA} \mathrm{~cm}^{-2}$ for certain preparations of $\mathrm{MoS}_{2} \cdot{ }^{21-24}$ These efforts include maximization of the areal exposure of active crystallographic sites; ${ }^{21,22,25,26}$ deposition of the active material onto structured (non-planar) supports; ${ }^{21,26,27}$ developing improvements in the conductivity of the materials; $;^{21,22,27}$ and alloying with other metals to promote intrinsic activity. ${ }^{28,29}$

The binary Co chalcogenides have not been investigated as thoroughly as their Mo analogues for catalysis of the HER, but several catalytically active preparations have been reported. ${ }^{30-33}$ Nanocrystalline thin films of $\mathrm{CoS}_{2}$ and $\mathrm{CoSe}_{2}$ synthesized by treating metallic Co films with $\mathrm{S}$ vapor at $550{ }^{\circ} \mathrm{C}$ or Se vapor at $450{ }^{\circ} \mathrm{C}$ have achieved a current density of $-4 \mathrm{~mA} \mathrm{~cm}{ }^{-2}$ at overpotentials of $\sim 220 \mathrm{mV}$ and $200 \mathrm{mV}$, respectively, in $\mathrm{N}_{2}$ dearated $0.5 \mathrm{M} \mathrm{H}_{2} \mathrm{SO}_{4}$. Nanoparticle films of $\mathrm{CoSe}_{2}$ fabricated by 
treating $\mathrm{CoO}$ nanoparticles (initially formed by pyrolysis of an ink containing $\mathrm{Co}\left(\mathrm{NO}_{3}\right) \cdot 6 \mathrm{H}_{2} \mathrm{O}$ at $600{ }^{\circ} \mathrm{C}$ ) with Se vapor at $450{ }^{\circ} \mathrm{C}$ required an overpotential of $\sim 210 \mathrm{mV}$ to effect a current density of $-10 \mathrm{~mA} \mathrm{~cm}{ }^{-2}$ in $0.5 \mathrm{M} \mathrm{H}_{2} \mathrm{SO}_{4}$. Amorphous films of $\mathrm{Co}-\mathrm{S}$, composed of Co and $\mathrm{S}$ in a $\sim 1: 1.4$ atomic ratio, produced via electrodeposition followed by thermal annealing at $300{ }^{\circ} \mathrm{C}$ required an overpotential of $\sim 160 \mathrm{mV}$ to reach $-10 \mathrm{~mA} \mathrm{~cm}^{-2}$ in phosphate buffer at $\mathrm{pH}=7$, but rapidly deactivated in $0.5 \mathrm{M}$ $\mathrm{H}_{2} \mathrm{SO}_{4}$. Ni/NiO/CoSe 2 nanocomposites fabricated utilizing several hydrothermal, solvothermal and annealing steps at temperatures between 180 and $250{ }^{\circ} \mathrm{C}$ have been shown to reach $-10 \mathrm{~mA} \mathrm{~cm}{ }^{-2}$ with an overpotential $<100 \mathrm{mV}$ in Ar-saturated 0.5 $\mathrm{M} \mathrm{H}_{2} \mathrm{SO}_{4}$, but are unstable in such media. Methods that employ solution-based techniques for catalyst synthesis and assembly under ambient conditions are preferable to high temperature and/or vapor-based techniques because solution-based techniques require relatively low energy inputs and provide increased compatibility with substrates. We describe herein an electrochemical method for the preparation of catalytically active, amorphous cobalt selenide films, from fully oxidized precursors in aqueous solution under ambient conditions.

The cobalt selenide films were electrodeposited from an aqueous solution of $\mathrm{Co}\left(\mathrm{C}_{2} \mathrm{H}_{3} \mathrm{O}_{2}\right)_{2}$ and $\mathrm{SeO}_{2}$ using potentiostatic electrolysis, and were then conditioned in $0.500 \mathrm{M} \mathrm{H}_{2} \mathrm{SO}_{4}$ using galvanostatic electrolysis in the HER regime (see the ESI $\dagger$ for detailed Experimental methods). The cobalt selenide films were characterized by scanning electron microscopy (SEM), energydispersive X-ray spectroscopy (EDS), Raman spectroscopy, powder X-ray diffraction (XRD) and X-ray photoelectron spectroscopy (XPS). ${ }^{34,35}$ Fig. 1a shows a scanning electron micrograph of an electrochemically prepared film. The films were mesoporous and contained pores estimated to be $\sim 20 \mathrm{~nm}$ in diameter. Measurements made using EDS indicated a Co: Se atomic ratio of $1: 2$. The Raman spectrum (Fig. 1b) displayed no signatures of crystalline $\mathrm{CoSe}_{2}$ nor of Se, ${ }^{36,37}$ but contained a broad band centered at $\sim 233 \mathrm{~cm}^{-1}$ indicative of the stretching of Se-Se bonds in glassy selenium comprised of close-packed chains in which the local microscopic structure resembles that of crystalline, trigonal Se. ${ }^{38}$ The Raman spectrum also exhibited a less intense, lower frequency feature, centered at $\sim 166 \mathrm{~cm}^{-1}$, consistent with expectations for the bending of the Se-Se bonds in the close-packed chains as well as the presence of disordered CoSe. ${ }^{39,40}$ No signals were observed from oxygenated cobalt species. ${ }^{41-43}$ The Raman spectrum was consistent with the XRD pattern obtained for the film (Fig. S1†), which only exhibited reflections that corresponded to the Ti substrate and did not show reflections that corresponded to any crystalline cobalt selenide species. High-resolution XPS analysis of the Co 2p region (Fig. S2a †) displayed an intense Co $2 \mathrm{p}_{3 / 2}$ line at $781.5 \mathrm{eV}$ which was not consistent with expectations for $\mathrm{CoSe}_{2} \cdot{ }^{44}$ XPS analysis of the Se $3 d$ region (Fig. $\mathrm{S} 2 \mathrm{~b} \dagger$ ) revealed the presence of $\mathrm{Se}$ in both the $\mathrm{Se}^{0}$ and $\mathrm{Se}^{2-}$ oxidation states. Thus, the cumulative data suggest that the films were composed of disordered CoSe in a polymeric Se matrix.

Fig. 2a presents the cathodic polarization behavior of a cobalt selenide film, as well as that of a bare titanium substrate, in a three-electrode voltammetric configuration in an aqueous
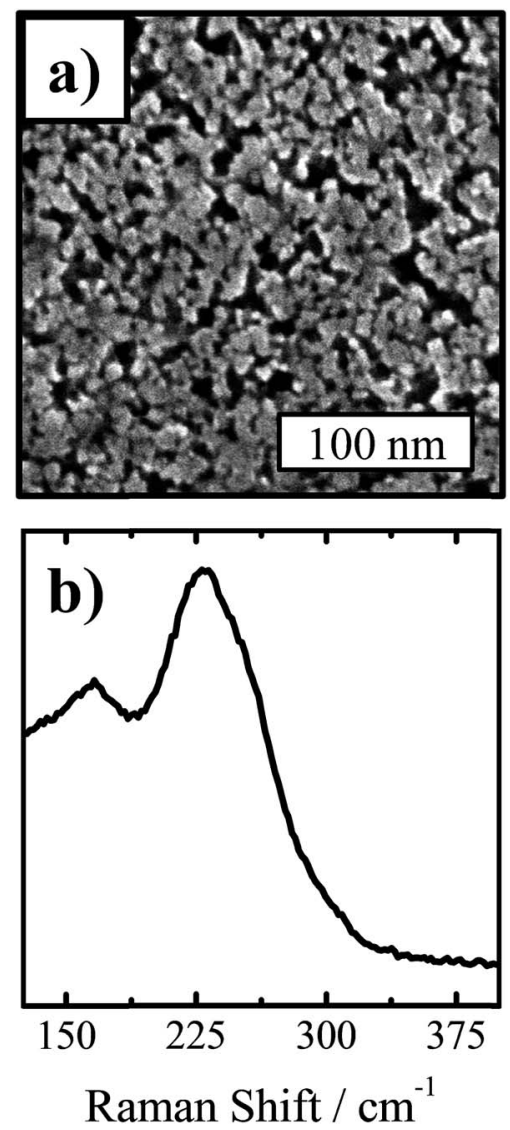

Fig. 1 Representative (a) scanning electron micrograph and (b) Raman spectrum of an electrochemically prepared cobalt selenide film.

solution of $0.500 \mathrm{M} \mathrm{H}_{2} \mathrm{SO}_{4}$ that was saturated with 1 atm of $\mathrm{H}_{2}(\mathrm{~g})$. The overpotentials required to produce current densities of $-10 \mathrm{~mA} \mathrm{~cm}^{-2}$ and $-25 \mathrm{~mA} \mathrm{~cm} \mathrm{~cm}^{-2}$ at a cobalt selenide film were $135 \pm 2 \mathrm{mV}$ and $160 \pm 3 \mathrm{mV}$ (mean \pm s.d.), respectively, based on six independently prepared films. The Ti substrate exhibited negligible current densities throughout the interrogated potential window. Ti is an ineffective HER catalyst and thus provides a clean background for interrogating the HER activity of other materials. Fig. 2b presents a Tafel plot (overpotential versus $\log [\mid$ current density|]) derived from the voltammetric data of Fig. 2a. A Tafel slope of $62 \mathrm{mV} \mathrm{dec}{ }^{-1}$ and an exchange current density of $6.4 \times 10^{-2} \mathrm{~mA} \mathrm{~cm}^{-2}$ were derived from the region between 110 and $180 \mathrm{mV}$ in overpotential. The $62 \mathrm{mV} \mathrm{\operatorname {dec } ^ { - 1 }}$ Tafel slope is inconsistent with the predicted values for the HER in acidic solution at room temperature

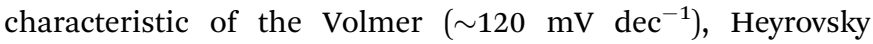

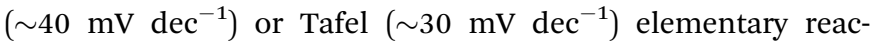
tions. ${ }^{45,46}$ Slopes of $\sim 60 \mathrm{mV} \mathrm{dec}{ }^{-1}$ may be observed when either the Heyrovsky or the Tafel reaction is rate-limiting if the adsorption of hydrogen atoms onto the electrode requires an activation energy. ${ }^{47}$ The $\sim 60 \mathrm{mV} \mathrm{dec}{ }^{-1}$ Tafel slope is consistent with the value observed for several amorphous molybdenum sulfide catalysts. ${ }^{34,35}$ Turnover frequencies (TOFs) exhibited by the cobalt selenide films for the HER were derived from the voltammetric data by a method previously reported for an 

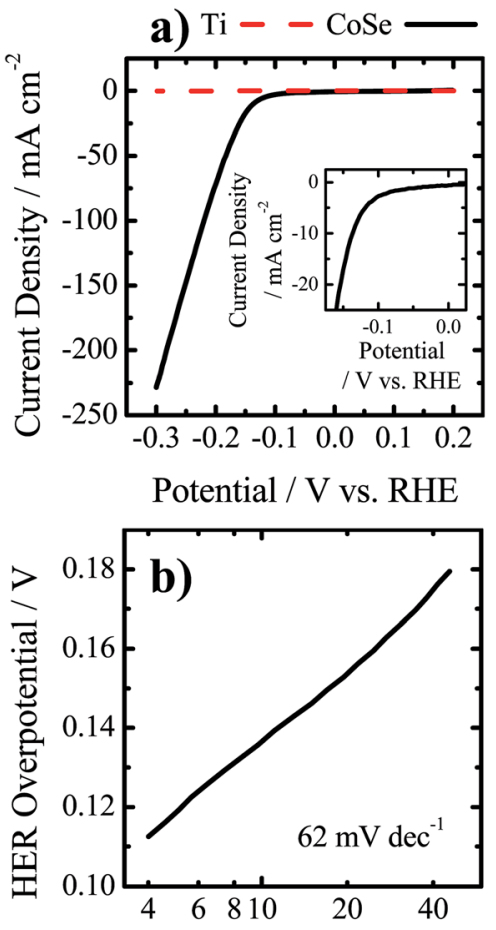

$\mid$ Current Density $\mid / \mathrm{mA} \mathrm{cm}^{-2}$

Fig. 2 (a) Cathodic polarization curves of titanium foil and of a cobalt selenide film in $0.500 \mathrm{M} \mathrm{H}_{2} \mathrm{SO}_{4}$ saturated with $\mathrm{H}_{2}(\mathrm{~g})$ (inset highlights behavior at low overpotentials). (b) Tafel plot derived from data in (a).

amorphous molybdenum sulfide film (see the ESI $\dagger$ for calculation details). ${ }^{35} \mathrm{~A}$ plot of the TOF as a function of HER overpotential is presented in Fig. S3. $\dagger$ TOF values were estimated to be $1 \mathrm{~s}^{-1}$ at an overpotential of $100 \mathrm{mV}$ and $5 \mathrm{~s}^{-1}$ at an overpotential of $150 \mathrm{mV}$.

The stability of the as-prepared CoSe films during electrochemical hydrogen evolution was assessed by two independent experimental protocols. First, a current density of -10 $\mathrm{mA} \mathrm{cm}{ }^{-2}$ was maintained galvanostatically and the electrode potential was monitored as a function of time (Fig. 3a). Over $16 \mathrm{~h}$ of continuous operation, the overpotential required to maintain this current density increased by $\sim 5 \mathrm{mV}$. Separately, an accelerated degradation study ${ }^{21,32}$ was performed wherein the electrode potential was swept repeatedly between 0.100 and $-0.175 \mathrm{~V}$ vs. RHE for 1000 full cycles. Voltammograms recorded before and after cycling (Fig. $3 \mathrm{~b}$ ) revealed that the overpotential required to achieve current densities of $-10 \mathrm{~mA}$ $\mathrm{cm}^{-2}$ and $-25 \mathrm{~mA} \mathrm{~cm}{ }^{-2}$ increased by less than $5 \mathrm{mV}$ in both cases. The catalytic stability of the CoSe films during the HER in $0.5 \mathrm{M} \mathrm{H}_{2} \mathrm{SO}_{4}$ is consistent with that displayed by polycrystalline cobalt diselenide films prepared by treating metallic cobalt films with Se vapor, but is in contrast to that displayed by electrodeposited amorphous $\mathrm{Co}-\mathrm{S}$ films which quickly dissolve under these conditions. ${ }^{31,32}$ These observations are consistent with the fact that in solutions with $\mathrm{pH}<4$, Se is cathodically stable until at least $-0.4 \mathrm{~V} v s$. RHE, whereas the reduction of $\mathrm{S}$ to $\mathrm{H}_{2} \mathrm{~S}$ is thermodynamically possible at potentials $>0 \mathrm{~V} v s$. RHE. ${ }^{48}$

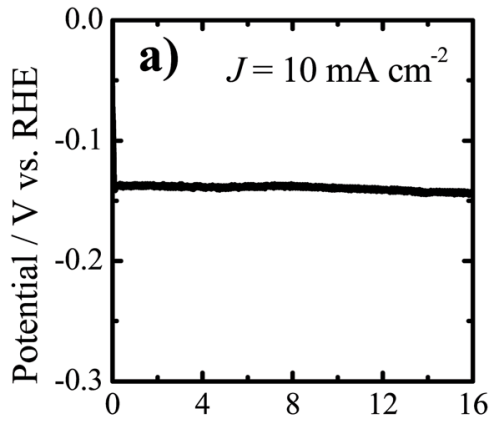

Time / h

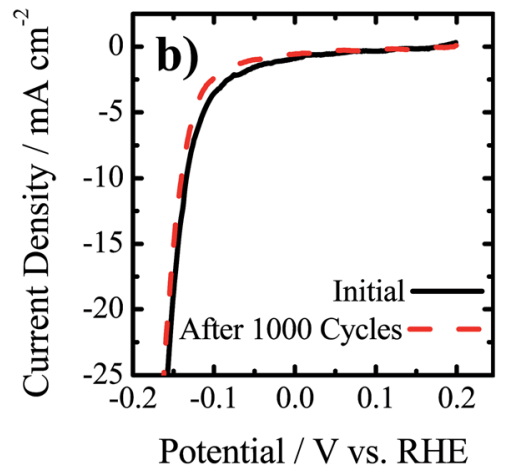

Fig. 3 (a) Potential applied to a cobalt selenide film as a function of time during galvanostatic electrolysis at $-10 \mathrm{~mA} \mathrm{~cm}^{-2}$ in $0.500 \mathrm{M}$ $\mathrm{H}_{2} \mathrm{SO}_{4}$ (b) Polarization curves of a cobalt selenide film acquired before and after 1000 accelerated full potential cycles between $0.100 \mathrm{~V}$ and $-0.175 \mathrm{~V}$ vs. RHE.

The $\sim 135 \mathrm{mV}$ overpotential for effecting current densities of $-10 \mathrm{~mA} \mathrm{~cm}^{-2}$ in $0.500 \mathrm{M} \mathrm{H}_{2} \mathrm{SO}_{4}$ exhibited by the cobalt selenide films described in this work compares well to the values for other stable and highly-active catalyst materials in acidic media that are composed of Earth-abundant elements. Defective and disordered ultrathin nanosheets of $\mathrm{MoS}_{2}$ as well as nanosheets of the $1 \mathrm{~T}-\mathrm{MoS}_{2}$ polymorph have been demonstrated to achieve $-10 \mathrm{~mA} \mathrm{~cm} \mathrm{~cm}^{-2}$ with overpotentials in the range of $180-$ $190 \mathrm{mV}^{.22-24} \mathrm{MoS}_{2} /$ reduced graphene oxide composites have reached current densities of $-10 \mathrm{~mA} \mathrm{~cm}{ }^{-2}$ with an overpotential of $\sim 160 \mathrm{mV}^{21} \mathrm{Ni}_{2} \mathrm{P}$ nanoparticles have been shown to drive current densities of $-10 \mathrm{~mA} \mathrm{~cm}{ }^{-2}$ with an overpotential of $\sim 120 \mathrm{mV} .{ }^{16}$ Notably, the cobalt selenide films described herein were prepared entirely at room temperature and ambient conditions, via a facile electrochemical method. Also, as synthesized, the amorphous Se matrix containing the CoSe may not act as a good electrical conductor, so the activity reported in this work may represent a lower bound on the true electrocatalytic activity of the material. ${ }^{49}$ Additionally, high-surface area substrates were not utilized to improve the geometric current densities of the CoSe films in this work. $\mathrm{Mo}_{2} \mathrm{C}$ supported on carbon nanotubes and amorphous $\operatorname{MoS}_{x}$ coated on $\mathrm{N}$-doped carbon nanotubes have been shown to effect current densities of $-10 \mathrm{~mA} \mathrm{~cm}^{-2}$ with overpotentials of $\sim 150 \mathrm{mV}$ and $110 \mathrm{mV}$, respectively. ${ }^{50,51}$ Similarly, nanoparticles of $\mathrm{CoSe}_{2}$ have achieved $-10 \mathrm{~mA} \mathrm{~cm}{ }^{-2}$ with an overpotential of $137 \mathrm{mV}$ when deposited on a high-surface area, porous, three-dimensional 
electrode (carbon fiber paper). ${ }^{33}$ Fabrication of a similar structured composite with electrochemically prepared cobalt selenide may thus lead to improved performance. Similarly, deposition with dynamic potential-time waveforms, as well as alloying with $\mathrm{Fe}$ or $\mathrm{Ni}$ as has been done to promote the activity of molybdenum sulfide, could also prove effective for increasing the activity of cobalt selenide-based materials. ${ }^{28,29}$

In conclusion, cobalt selenide films prepared by a simple electrochemical method under ambient conditions have demonstrated significant electrocatalytic activity and stability for catalysis of the HER in strongly acidic aqueous solution. This work suggests that electrochemically synthesized metal chalcogenide materials are promising catalysts for applications involving the HER, especially for applications involving the direct production of fuels from sunlight in solar-driven watersplitting systems. ${ }^{5,52}$ Moreover, investigations of deposition on structured supports, complex potential-time waveforms for electrodeposition, and alloying with other transition metals, as have been demonstrated for $\mathrm{MoS}_{2}$, may result in further enhancements of the HER activity of such materials. ${ }^{27,34}$

\section{Acknowledgements}

This material is based in part upon work performed by the Joint Center for Artificial Photosynthesis, a DOE Energy Innovation Hub, supported through the Office of Science of the U. S. Department of Energy under Award Number DE-SC0004993. The authors gratefully acknowledge Dr S. Mitrovic for assistance with X-ray photoelectron spectra acquisition, R. Gerhart for assistance with cell fabrication and Dr J. H. Baricuatro for insightful discussions. AIC recognizes a Graduate Research Fellowship from the National Science Foundation for support.

\section{References}

1 S. Schuldiner, J. Electrochem. Soc., 1952, 99, 488-494.

2 J. P. Hoare and S. Schuldiner, J. Electrochem. Soc., 1955, 102, 485-489.

3 M. G. Walter, E. L. Warren, J. R. McKone, S. W. Boettcher, Q. Mi, E. A. Santori and N. S. Lewis, Chem. Rev., 2010, 110, 6446-6473.

4 T. R. Cook, D. K. Dogutan, S. Y. Reece, Y. Surendranath, T. S. Teets and D. G. Nocera, Chem. Rev., 2010, 110, 64746502.

5 J. R. McKone, N. S. Lewis and H. B. Gray, Chem. Mater., 2014, 26, 407-414.

6 J. R. McKone, S. C. Marinescu, B. S. Brunschwig, J. R. Winkler and H. B. Gray, Chem. Sci., 2014, 5, 865-878.

7 S. Grigoriev, V. Porembsky and V. Fateev, Int. J. Hydrogen Energy, 2006, 31, 171-175.

8 E. A. Hernández-Pagán, N. M. Vargas-Barbosa, T. Wang, Y. Zhao, E. S. Smotkin and T. E. Mallouk, Energy Environ. Sci., 2012, 5, 7582-7589.

9 D. E. Brown, M. N. Mahmood, M. C. M. Man and A. K. Turner, Electrochim. Acta, 1984, 29, 1551-1556.

10 C. Fan, D. L. Piron, A. Sleb and P. Paradis, J. Electrochem. Soc., 1994, 141, 382-387.
11 C. Fan, D. L. Piron and P. Paradis, Electrochim. Acta, 1994, 39, 2715-2722.

12 J. R. McKone, B. F. Sadtler, C. A. Werlang, N. S. Lewis and H. B. Gray, ACS Catal., 2013, 3, 166-169.

13 W. F. Chen, K. Sasaki, C. Ma, A. I. Frenkel, N. Marinkovic, J. T. Muckerman, Y. Zhu and R. R. Adzic, Angew. Chem. Int. Ed., 2012, 51, 6131-6135.

14 B. Cao, G. M. Veith, J. C. Neuefeind, R. R. Adzic and P. G. Khalifah, J. Am. Chem. Soc., 2013, 135, 19186-19192.

15 H. Vrubel and X. Hu, Angew. Chem., Int. Ed., 2012, 51, 1270312706.

16 E. J. Popczun, J. R. McKone, C. G. Read, A. J. Biacchi, A. M. Wiltrout, N. S. Lewis and R. E. Schaak, J. Am. Chem. Soc., 2013, 135, 9267-9270.

17 G. C. Dismukes, personal communication.

18 E. J. Popczun, C. G. Read, C. W. Roske, N. S. Lewis and R. E. Schaak, Angew. Chem. Int. Ed., 2014, 53, 5427-5430.

19 B. Hinnemann, P. G. Moses, J. Bonde, K. P. Jørgensen, J. H. Nielsen, S. Horch, I. Chorkendorff and J. K. Nørskov, J. Am. Chem. Soc., 2005, 127, 5308-5309.

20 D. Merki and X. Hu, Energy Environ. Sci., 2011, 4, 3878-3888. 21 Y. Li, H. Wang, L. Xie, Y. Liang, G. Hong and H. Dai, J. Am. Chem. Soc., 2011, 133, 7296-7299.

22 M. A. Lukowski, A. S. Daniel, F. Meng, A. Forticaux, L. Li and S. Jin, J. Am. Chem. Soc., 2013, 135, 10274-10277.

23 J. Xie, H. Zhang, S. Li, R. Wang, X. Sun, M. Zhou, J. Zhou, X. W. Lou and Y. Xie, Adv. Mater., 2013, 25, 5807-5813.

24 J. Xie, J. Zhang, S. Li, F. Grote, X. Zhang, H. Zhang, R. Wang, Y. Lei, B. Pan and Y. Xie, J. Am. Chem. Soc., 2013, 135, 1788117888.

25 D. Kong, H. Wang, J. J. Cha, M. Pasta, K. J. Koski, J. Yao and Y. Cui, Nano Lett., 2013, 13, 1341-1347.

26 H. Wang, D. Kong, P. Johanes, J. J. Cha, G. Zheng, K. Yan, N. Liu and Y. Cui, Nano Lett., 2013, 13, 3426-3433.

27 Z. Chen, D. Cummins, B. N. Reinecke, E. Clark, M. K. Sunkara and T. F. Jaramillo, Nano Lett., 2011, 11, 4168-4175.

28 D. Merki, H. Vrubel, L. Rovelli, S. Fierro and X. Hu, Chem. Sci., 2012, 3, 2515-2525.

29 X.-J. Lv, G.-W. She, S.-X. Zhou and Y.-M. Li, RSC Adv., 2013, 3, 21231-21236.

30 Y. F. Xu, M. R. Gao, Y. R. Zheng, J. Jiang and S. H. Yu, Angew. Chem. Int. Ed., 2013, 52, 8546-8550.

31 Y. Sun, C. Liu, D. C. Grauer, J. Yano, J. R. Long, P. Yang and C. J. Chang, J. Am. Chem. Soc., 2013, 135, 17699-17702.

32 D. Kong, J. J. Cha, H. Wang, H. R. Lee and Y. Cui, Energy Environ. Sci., 2013, 6, 3553-3558.

33 D. Kong, H. Wang, Z. Lu and Y. Cui, J. Am. Chem. Soc., 2014, 136, 4897-4900.

34 D. Merki, S. Fierro, H. Vrubel and X. Hu, Chem. Sci., 2011, 2, 1262-1267.

35 J. D. Benck, Z. Chen, L. Y. Kuritzky, A. J. Forman and T. F. Jaramillo, ACS Catal., 2012, 2, 1916-1923.

36 E. Anastassakis, Solid State Commun., 1973, 13, 12971301.

37 G. Lucovsky, A. Mooradian, W. Taylor, G. B. Wright and R. C. Keezer, Solid State Commun., 1967, 5, 113-117. 
38 S. N. Yannopoulos and K. S. Andrikopoulos, J. Chem. Phys., 2004, 121, 4747-4758.

39 S. N. Yannopoulos and K. Andrikopoulos, Phys. Rev. B, 2004, 69, 114206.

40 C. E. M. Campos, J. C. de Lima, T. A. Grandi, K. D. Machado and P. S. Pizani, Physica B, 2002, 324, 409-418.

41 V. G. Hadjiev, M. N. Iliev and I. V. Vergilov, J. Phys. C: Solid State Phys., 1988, 21, L199-L201.

42 D. Gallant, M. Pézolet and S. Simard, J. Phys. Chem. B, 2006, 110, 6871-6880.

43 J. Tyczkowski, R. Kapica and J. Łojewska, Thin Solid Films, 2007, 515, 6590-6595.

$44 \mathrm{H}$. van der Heide, R. Hemmel, C. F. van Bruggen and C. Haas, J. Solid State Chem., 1980, 33, 17-25.

45 N. Pentland, J. O. Bockris and E. Sheldon, J. Electrochem. Soc., 1957, 104, 182-194.
46 B. E. Conway and B. V. Tilak, Electrochim. Acta, 2002, 47, 3571-3594.

47 J. G. N. Thomas, Trans. Faraday Soc., 1961, 57, 16031611.

48 M. Pourbaix, Atlas of Electrochemical Equilibria In Aqueous Solutions, Permagon Press, Oxford, 1966.

49 K. E. Murphy, B. B. Wunderlich and B. Wunderlich, J. Phys. Chem., 1982, 86, 2827-2835.

50 W. F. Chen, C. H. Wang, K. Sasaki, N. Marinkovic, W. Xu, J. T. Muckerman, Y. Zhu and R. R. Adzic, Energy Environ. Sci., 2013, 6, 943-951.

51 D. J. Li, U. N. Maiti, J. Lim, D. S. Choi, W. J. Lee, Y. Oh, G. Y. Lee and S. O. Kim, Nano Lett., 2014, 14, 1228-1233.

52 S. Haussener, C. Xiang, J. M. Spurgeon, S. Ardo, N. S. Lewis and A. Z. Weber, Energy Environ. Sci., 2012, 5, 99229935. 